\title{
Enhancement of osteoclastogenic activity in osteolytic prostate cancer cells by physical contact with osteoblasts
}

\author{
A Shiirevnyamba',2, T Takahashi', H Shan', H Ogawa', S Yano ${ }^{3}$, H Kanayama ${ }^{2}$, K Izumi' and H Uehara*,I \\ 'Department of Molecular and Environmental Pathology, The University of Tokushima Graduate School, 3-1 8-15, Kuramoto-cho, Tokushima 770-8503, \\ Japan; ${ }^{2}$ Department of Urology, Institute of Health Biosciences, The University of Tokushima Graduate School, 3-1 8-15, Kuramoto-cho, Tokushima \\ 770-8503, Japan; ${ }^{3}$ Division of Medical Oncology, Cancer Research Institute, Kanazawa University, Kanazawa, Ishikawa 920-0934, Japan
}

\begin{abstract}
BACKGROUND: The interaction between prostate cancer cells and osteoblasts is critical for the development of bone metastasis. Metastatic cancer cells may physically contact osteoblasts in the bone microenvironment; however, the biological significance of this interaction is not fully understood.

METHODS: Human prostate cancer cells (the osteolytic cell line PC-3 and the osteoblastic cell line MDA-PCa 2b) and human osteoblasts (hFOBI. 19) were cocultured under two different conditions (bilayer and contact conditions). Differential gene expression profiles of prostate cancer cells were then investigated using microarray analysis. Differentially expressed genes were analysed using RT-PCR and western blotting, and the effect of anti-cadherin neutralising antibodies on their expression was assayed. The osteoclastogenic activity of cells grown under these different conditions was also investigated using an in vitro assay.

RESULTS: When PC-3 or MDA-PCa $2 b$ cells were cocultured with hFOBI. 19 cells under contact conditions, the expression of eight genes was upregulated and that of one gene was downregulated in PC-3 cells compared with gene expression in bilayer culture. No differentially expressed genes were detected in MDA-PCa $2 b$ cells. Four of the eight upregulated genes (interleukin-I $\beta$ (IL-I $\beta$ ), cyclooxygenase-2 (COX-2), IL-6 and the third component of complement (C3)) have already been reported to participate in osteoclastogenesis. Indeed, a cell lysate of PC-3 cells grown under contact coculture conditions significantly enhanced osteoclastogenesis in vitro $(P<0.005)$. neutralisation of cadherin-I I with a specific antibody inhibited upregulation of $C O X-2$ and C3 mRNA in PC-3 cells. In contrast, neutralisation of N-cadherin induced upregulation of COX-2 mRNA.

CONCLUSION: Physical contact between osteolytic prostate cancer cells and osteoblasts may upregulate osteoclastogenesis-related gene expression in prostate cancer cells and enhance osteoclastogenesis. Additionally, cadherin-I I and N-cadherin are involved in this process. These data provide evidence supporting new therapies of prostate cancer bone metastasis that target direct cancer-cellosteoblast cell-cell contact.
\end{abstract}

British Journal of Cancer (20II) I 04, 505-5I3. doi:I0.I038/sj.bjc.6606070 www.bjcancer.com

Published online 4 January $201 \mathrm{I}$

(C) 20II Cancer Research UK

Keywords: physical contact; cell-to-cell interaction; prostate cancer; bone metastasis; osteoclastogenesis

Prostate cancer continues to be the most common cancer, and the second leading cause of cancer deaths, among American men. Despite earlier diagnosis and refinements in surgery and radiation, it was estimated that 28660 men would die from prostate cancer in the United States in 2008 (Jemal et al, 2008). Moreover, there has been a recent trend towards an increased incidence of prostate cancer in Asia, although the rate of prostate cancer in Asia is still much lower than that in the United States or in many European countries (Sim and Cheng, 2005). Bone metastasis of prostate cancer is the major cause of morbidity and mortality, and was detected at autopsy in up to $90 \%$ of patients who died from prostate cancer (Bubendorf et al, 2000). Metastasis of prostate cancer cells to bone is a multistep process including detachment of cancer cells from the primary site, travel of the cells in the blood or

\footnotetext{
*Correspondence: Dr H Uehara;

E-mail: uehara@basic.med.tokushima-u.ac.jp

Received I6 July 20 I0; revised I5 October 2010; accepted I December 20I0; published online 4 January $201 \mathrm{I}$
}

lymph, attachment to bone tissue and development of a tumour at the site of the bone metastasis. Prostate cancer metastases cause an osteoblastic (excessive bone forming), osteolytic (bone lysing) or mixed bone response (Charhon et al, 1983; Cheville et al, 2002; Roudier et al, 2003).

The interaction between prostate cancer cells and normal cells in a bone microenvironment is important for survival and proliferation of metastatic cancer cells. It has been shown that factors secreted by prostate cancer cells alter bone homoeostasis by disrupting a balance between osteoblastic and osteoclastic activity (Roudier et al, 2003; Logothetis and Lin, 2005; Morrissey et al, 2010). In turn, osteoblasts and osteoclasts secrete factors that facilitate progression of prostate cancer in bone (Lang et al, 1995; Yin et al, 2005). Once prostate cancer cells have metastasised to bone marrow, the cancer cells are suspected to interact with osteoblasts, osteoclasts and stromal cells thorough both soluble factors and physical contact. Interaction mediated by soluble factors has been studied using in vitro coculture systems. In those studies, the conditioned medium of cancer cells, or bilayer condition using a cell culture insert, was used for coculture 
(Martínez et al, 1996; Kido et al, 1997; Hullinger et al, 2000; Fizazi et al, 2003). However, there have been few studies of the mechanism by which prostate cancer cells physically contact normal cells in a bone microenvironment. Wang et al (2006) established a novel physical contact coculture system and showed that physical contact between prostate cancer cells and bone marrow stromal cells may act as an independent factor affecting the progression of bone metastasis. However, interaction between prostate cancer cells and other normal cells in the bone microenvironment remains unclear.

A variety of factors, such as morphogenetic proteins, adhesion molecules, chemotactic factors, cytokines and growth factors, are known to be involved in the metastasis of prostate cancer to bone (Mundy, 2002; Roodman, 2004). Adhesion molecules, in particular, may have a crucial role in the interaction between prostate cancer cells and normal cells in the bone microenvironment. N-cadherin and cadherin-11 are highly expressed in prostate cancer cells and osteoblasts, but not in normal prostate tissue. Cadherin-11 promotes bone metastasis in a mouse model and its expression increases as the tumour progresses from primary prostate cancer to metastatic disease in lymph nodes and especially in bone (Gravdal et al, 2007; Chu et al, 2008). Therefore, heterotypic interactions between cancer cells and osteoblasts mediated through homophilic adhesion molecules may have a role in bone metastasis formation and progression, although the underlying mechanisms are not fully understood. It is absolutely crucial to precisely understand these molecular mechanisms in order to develop new therapies for bone metastasis.

In this study, we compared gene expression of prostate cancer cells that produce either osteoblastic or osteolytic lesions, after coculture with osteoblasts using two different coculture systems. Our study reveals that physical contact between osteolytic prostate cancer cells and osteoblasts may upregulate the expression of specific osteoclastogenesis-related genes in prostate cancer cells and enhance osteoclastogenesis. Additionally, at least in part, this process is cadherin-11 dependent.

\section{MATERIALS AND METHODS}

\section{Histological analysis of bone metastasis in autopsy cases}

A total of 229 autopsy cases were reviewed and 37 various cancer cases with bone metastasis (including two of prostate cancer) were selected for further analysis. Autopsies had been performed at Tokushima University Hospital between 2003 and 2008.

\section{Cells and animals}

The PC-3 human prostate cancer cell line was obtained from the Health Science Research Resources Bank (Osaka, Japan). The MDA-PCa 2b human prostate cancer cell line and hFOB1.19 immortalised human osteoblastic cell line were from the American Type Cell Culture Collection (Manassas, VA, USA). Both the PC-3 and the MDA-PCa $2 \mathrm{~b}$ cell line were established from bone metastases, but the in vivo growth pattern of PC-3 cells is osteolytic (Uehara et al, 2003), whereas that of MDA-PCa 2 b cells is osteoblastic (Fizazi et al, 2003). The hFOB1.19 cells were transfected with a gene coding for a temperature-sensitive mutant (tsA58) of the SV40 large T antigen and exhibit rapid growth at $33.5^{\circ} \mathrm{C}$ (Harris et al, 1995). Before coculture studies, we confirmed the mRNA expression of alkaline phosphatase and osteocalcin, markers of osteoblastic differentiation, in hFOB1.19 cells at $37^{\circ} \mathrm{C}$ using RT-PCR (data not shown). The PC-3 cell line was maintained in MEM supplemented with $10 \%$ fetal bovine serum (FBS), MDA-PCa 2b was maintained in BRFF-HPC1 (Athena Environmental Sciences, Baltimore, MD, USA) with $20 \%$ FBS and hFOB1.19 was maintained in phenol red-free DMEM/F12 supplemented with $10 \%$ FBS. Penicillin G $\left(100 \mathrm{U} \mathrm{ml}^{-1}\right)$ and streptomycin sulphate $\left(0.1 \mathrm{mg} \mathrm{ml}^{-1}\right)$ were added to all conditioned media. Male BALB/c mice (6-10 weeks old) and BALB/c nude mice (5 weeks old) were purchased from Crea Japan (Tokyo, Japan). Mice were housed and maintained under specific pathogen-free conditions. Experiments were performed according to the Guideline for the Care and Use of Laboratory Animals of the University of Tokushima School of Medicine, and were approved by the Animal Care and Use Committee.

\section{Xenograft model of osteolytic bone metastasis}

PC-3 cells $\left(5 \times 10^{5}\right.$ per mice $)$ were injected into the proximal tibiae of nude mice under anaesthesia that consisted of a mixture of ketamine hydrochloride and xylazine. After 5-9 weeks, the mice were killed and the hind limbs were excised at the knee joint, fixed in $10 \%$ phosphate-buffered formaldehyde at room temperature for $24 \mathrm{~h}$, and then decalcified with $10 \%$ EDTA (pH 7.4) at $4^{\circ} \mathrm{C}$ for 2 weeks. The tissues were then embedded in paraffin, sectioned and subjected to $\mathrm{H} \& \mathrm{E}$ staining and immunohistochemical staining.

\section{Coculture assay and fluorescence-activated cell sorting}

Prostate cancer cells and hFOB1.19 cells were cocultured in contact and bilayer cocultures. Before coculture, the prostate cancer cells (PC-3 and MDA-PCa 2b cells) and hFOB1.19 cells were treated with $10 \mu \mathrm{g} \mathrm{ml}^{-1}$ of the fluorescent dye $\operatorname{DiOC}_{18}(3)$ or $\operatorname{DiIC}_{18}(3)$ (Invitrogen, Carlsbad, CA, USA) for $48 \mathrm{~h}$. In the contact coculture, the prostate cancer cells were mixed and cocultured with hFOB1.19 cells in serum- and phenol red-free DMEM/F12 for $48 \mathrm{~h}$. The initial ratio of the cell numbers was set at $1: 1$. In the bilayer coculture, the prostate cancer cells were first seeded onto a 6-well plate $\left(4 \times 10^{5}\right.$ cells per well) and a cell culture insert (PET membrane, $0.4 \mu \mathrm{m}$ pore size, Falcon, Franklin Lakes, NJ, USA) was subsequently placed on the top of each well. Equal numbers of hFOB1.19 cells were seeded onto this insert and the plate was cultured for $48 \mathrm{~h}$. The medium used for this bilayer coculture was the same as that used for the contact coculture. In both types of coculture, the cells were harvested using $1 \mathrm{~mm}$ EDTA. Prostate cancer cells were isolated from the cocultured cell mixture using fluorescenceactivated cell sorting (FACS) and the EPICS XL-MCL (Beckman Coulter, Fullerton, CA, USA). The osteoblast fraction was simultaneously isolated.

\section{Immunocytochemical staining}

After contact coculture, some of the isolated prostate cancer cells and osteoblasts were reseeded onto MAS-coated slide glass (Matsunami Glass Ind., Osaka, Japan) and were incubated at $37^{\circ} \mathrm{C}$ for $24 \mathrm{~h}$. These cells were fixed in $95 \%$ ethanol at room temperature for $20 \mathrm{~min}$, and were then heated in $0.01 \mathrm{M}$ citrate buffer $(\mathrm{pH}$ 6.0) for $10 \mathrm{~min}$ in a pressure cooker for antigen retrieval. Immunocytochemical staining was performed using the ChemMate ENVISION kit/horseradish peroxidase (DakoCytomation, Carpenteria, CA, USA). A monoclonal SV40 T antigen antibody (PAb416; Calbiochem, Darmstadt, Germany), that reacts specifically with the SV40 large T antigen but not with SV40 small $\mathrm{T}$ antigen, was added to the slides at a dilution of $1: 100$, and was incubated for $1 \mathrm{~h}$ at room temperature. After washing with PBS, each slide was treated with horseradish peroxidase-conjugated secondary antibody for $40 \mathrm{~min}$. The signal was visualized using 3 , $3^{\prime}$-diaminobenzidine, and the cells were then counterstained with hematoxylin.

\section{Microarray analysis}

Total RNA from hFOB1.19, PC-3 and MDA-PCa 2b cells was isolated using an RNeasy Mini kit (QIAGEN, Valencia, CA, USA). 
Table I Primers for RT-PCR

\begin{tabular}{|c|c|c|c|c|}
\hline Marker & Forward $\left(5^{\prime}-3^{\prime}\right)$ & Reverse $\left(5^{\prime}-3^{\prime}\right)$ & Size (bp) & Reference \\
\hline $\mid \mathrm{L}-\mathrm{I} \beta$ & GAGCTCGCCAGTGAAATG & TGCATCGTGCACATAAGC & 336 & Takahashi et al, 2008 \\
\hline N-cadherin & GACAACATTCACTGCTCA & GAACTTCATAGATACCAG & 488 & Original \\
\hline Cadherin-II & CAAGTTACATCCACGAAG & ATCTCGGTTGTCTCTGAC & 488 & Original \\
\hline$\beta$-actin & TACAATGAGCTGCGTGTGG & AGATGGGCACAGTGTGGG & 226 & Takahashi et al, 2008 \\
\hline
\end{tabular}

Relative purity of the RNA was measured using an Agilent 2100 Bioanalyzer (Agilent Technologies, Santa Clara, CA, USA). RNA expression was analysed using a GeneChip Human Gene 1.0 ST Array (Affymetrix, Santa Clara, CA, USA). This microarray chip contains 28869 oligonucleotide probes for known and unknown genes. First strand cDNA was synthesised from $300 \mathrm{ng}$ of total RNA using GeneChip whole transcript (WT) cDNA Synthesis and Amplification kit (Affymetrix) according to the manufacturer's protocol. Complementary RNA $(10 \mu \mathrm{g})$ was input into the secondcycle cDNA reaction and then this CDNA was fragmented and endlabeled with the GeneChip WT Terminal Labelling kit (Affymetrix). Approximately $5.5 \mu \mathrm{g}$ of labelled DNA target was hybridised to the Affymetrix GeneChip Human Gene 1.0 ST Array at $45^{\circ} \mathrm{C}$ for $17 \mathrm{~h}$ on a GeneChip Hybridisation 640 (Affymetrix) according to the manufacturer's recommendation. Hybridized arrays were washed and stained on a GeneChip Fluidics Station 450, were scanned using a GeneChip Scanner $30007 \mathrm{G}$ (Affymetrix) and then CEL files were generated for each array. This analysis was supported by the Support Center for Advanced Medical Sciences, the University of Tokushima Graduate School, Institute of Health Biosciences.

\section{Semiquantitative RT-PCR}

RNA molecules identified in the microarray analysis were subjected to semiquantitative RT-PCR analysis. Aliquots $(2 \mu \mathrm{g}$ per reaction) were reverse-transcribed using SuperScript II reverse transcriptase and random hexamers (Invitrogen). This reaction was conducted at $42^{\circ} \mathrm{C}$ for $60 \mathrm{~min}$, after which the temperature was increased to $72^{\circ} \mathrm{C}$ for $15 \mathrm{~min}$. The total cDNA was then amplified using PCR by following a thermocycling program of $94^{\circ} \mathrm{C}$ for $10 \mathrm{~min}$ for initial denaturation, 28 cycles of $94^{\circ} \mathrm{C}$ for $30 \mathrm{~s}, 55^{\circ} \mathrm{C}$ for $1 \mathrm{~min}, 72^{\circ} \mathrm{C}$ for $1 \mathrm{~min}$ for amplification, and a final extension at $72^{\circ} \mathrm{C}$ for $10 \mathrm{~min}$. The sequences of these primers are listed in Table 1 . The RT - PCR products were separated by $1.5 \%$ agarose gel electrophoresis and were visualized using an UV transilluminator.

\section{ELISA and western blot analysis}

After sorting, cocultured PC-3 cells were resuspended in phosphatebuffered saline containing $1 \mathrm{~mm}$ phenylmethylsulfonyl fluoride and were lysed using an ultrasonic homogenizer. These homogenates were then centrifuged and the supernatants were used as protein samples. The protein concentrations of the samples were quantified using the DC Protein Assay kit (Bio-Rad, Hercules, CA, USA). Aliquots ( $8 \mu \mathrm{g}$ protein) were subjected to ELISA assays for IL-1 $\beta$ (Human IL-1 $\beta$ ELISA kit, Invitrogen), IL-6 (Quantikine human IL-6 immunoassay kit, R\&D Systems, Minneapolis, MN, USA) and C3 (AssayMax human complement C3 ELISA kit, Assaypro, St Charles, MO, USA). Aliquots ( $10 \mu \mathrm{g}$ protein) were also subjected to western blot analysis as described previously (Takahashi et al, 2008). Rabbit anti-COX-2 (Santa Cruz Biotechnology, Santa Cruz, CA, USA) and anti-actin (Sigma, St Louis, MO, USA) antibodies were used as the primary antibodies. Goat antirabbit IgG-horseradish peroxidase (Invitrogen) was employed as the secondary antibody. The dilutions used are as follows: antiCOX-2, 1:250; anti-actin, 1:10000; and anti-rabbit IgG-horseradish peroxidase, $1: 200000$. An immobilon western horseradish peroxidase substrate (Millipore, Billerica, MA, USA) was used to detect the signals.

\section{Immunohistochemical staining}

Paraffin sections ( $4 \mu \mathrm{m}$ ) of bone lesions from a xenograft model of osteolytic bone metastasis were deparaffinized in xylene and dehydrated through descending concentrations of ethanol. Antigen retrieval and immunostaining was performed according to the immunocytochemical staining protocol described above. A monoclonal mouse anti-COX-2 antibody (COX 229; Invitrogen) was used as the primary antibody at dilution of $1: 50$.

\section{In vitro osteoclastogenesis assay}

Bone marrow was collected from male BALB/c mice by flushing the femurs and tibias with serum-free DMEM. The cells were then washed twice in the same medium, were seeded onto a $100 \mathrm{~mm}$ dish and were cultured in $10 \%$ FBS-containing DMEM at $37^{\circ} \mathrm{C}$ for 1 week. During culture, the medium was changed every three days. Adherent cells were reseeded onto a 96-well microplate $\left(1 \times 10^{4}\right.$ cells per well), were preincubated at $37^{\circ} \mathrm{C}$ for $24 \mathrm{~h}$ and were then treated with each cell lysate from PC-3 cells cocultured with hFOB 1.19 cells under contact or bilayer conditions $(10 \mu \mathrm{g})$ in the presence of receptor activator for nuclear factor- $\kappa \mathrm{B}$ ligand (RANKL, R \& D systems, Mineapolis, MN, USA) and macrophage colony-stimulating factor (M-CSF) $\left(10 \mathrm{ng} \mathrm{ml}^{-1}\right.$; R\&D Systems) after changing to flesh complete medium. After incubation for 10 days, the cells were fixed in $5 \%$ phosphate-buffered formaldehyde at room temperature for $5 \mathrm{~min}$ and tartrate-resistant acid phosphatase (TRAP) staining was conducted to detect differentiated osteoclasts. The composition of the TRAP staining solution was described in our previous report (Takahashi et al, 2008). The number of TRAP-positive cells in more then five microscopic fields was counted at $\times 200$ magnification.

\section{Neutralisation assay}

PC-3 and hFOB1.19 cells were treated with $\operatorname{DiOC}_{18}(3)$ and $\mathrm{DiIC}_{18}(3)$, respectively. The conditions of treatment were the same as described above. Before contact coculture, the hFOB1.19 cells were treated with $40 \mu \mathrm{g} \mathrm{ml}^{-1}$ of neutralising anti-N-cadherin (Sigma) or anti-Cadherin-11 (R\&D Systems) antibody, or of the corresponding isotype IgG for $30 \mathrm{~min}$ at $37^{\circ} \mathrm{C}$. These antibodytreated hFOB1.19 cells and PC-3 cells were mixed and cocultured in serum- and phenol red-free DMEM/F12 for $48 \mathrm{~h}$. The initial ratio of cell numbers was set at $1: 1$. PC- 3 cells were isolated using FACS sorting as described above. Isolated PC-3 cells were used for semiquantitative RT - PCR analyses for COX-2, IL-1 $\beta$, IL-6 and C3 mRNA. Calculations of signal intensities were performed by using NIHimage 1.62 software (http://rsbweb.nih.gov/nih-image/). 


\section{Statistical analyses}

A two-tailed Student's $t$-test was employed for statistical analyses of the data. Significant results were determined at a $P<0.05$.

\section{RESULTS}

\section{Histological findings of direct cancer-cell-osteoblast contact in bone metastasis}

We first determined if cancer-cell-osteoblast cell-cell contact could be observed in bone lesions in a xenograft model of osteolytic bone metastasis. Bone surfaces facing tumours were extensively lysed by osteoclasts. However, in some areas, residual osteoblasts were observed very close to cancer cells suggesting direct cancer-cell-osteoblast contact (Figure 1A and B).

We next determined how often direct cancer-cell-osteoblast contact occurs in human tumours, by reviewing H\&E-stained slides of 37 autopsy cases with bone metastases. The primary tumour sites of these cases were as follows: lung (17 cases), large intestine (4 cases), gallbladder (3 cases), pancreas, bladder and prostate ( 2 cases each), pleura, breast, stomach, liver, bile duct, kidney and soft tissue (1 case each). The bone metastases in the two case of prostate cancer were osteoblastic, and those in the other cases were osteolytic. The close proximity of cancer cells to osteoblasts suggesting direct cancer-cell-osteoblast contact was also observed to varying extents in all cases (Figure $1 \mathrm{C}$ and D).

\section{Immunocytochemical staining of the SV 40 large $\mathrm{T}$ antigen}

To further analyze cancer-cell-osteoblast contact, the human prostate cancer cells (PC-3 and MDA-PCa 2b calls) and hFOB1.19 osteoblasts, which were labelled with $10 \mu \mathrm{g} \mathrm{ml}^{-1}$ of the fluorescent dye $\operatorname{DiOC}_{18}(3)$ and $\operatorname{DiIC}_{18}(3)$, respectively, were cocultured in contact or in bilayer cocultures for $48 \mathrm{~h}$. Following coculture in contact cocultures, the prostate cancer cells and osteoblasts were then separated by sorting for further analyses. To confirm the purity of separated cell populations $\left(\mathrm{DiOC}_{18}(3)\right.$-labeled human prostate cancer cells and $\mathrm{DiIC}_{18}(3)$-labeled human osteoblasts) after sorting, the cells were immunocytochemically stained for the SV40 large T antigen, which is a marker of hFOB1.19 cells. As shown in Figure 2, the nuclei of hFOB1.19 cells $\left(\mathrm{DiOC}_{18}(3)^{-}\right.$/ $\mathrm{DiIC}_{18}(3)^{+}$) stained positive for the SV40 large $\mathrm{T}$ antigen, whereas no positive staining of PC-3 or MDA-PCa $2 \mathrm{~b}$ cells $\left(\mathrm{DiOC}_{18}(3)^{+} /\right.$ $\operatorname{DiIC}_{18}(3)^{-}$) was observed (MDA-PCa $2 \mathrm{~b}$ cells are not shown in Figure 2). Thus, prostate cancer cells and osteoblasts can be completely separated by sorting after coculture in contact cocultures.

\section{Gene expression analysis}

We next performed cDNA microarray analysis of prostate cancer cells that had been cocultured with osteoblasts, to identify differential gene expression in prostate cancer cells because of physical contact with the osteoblasts. We compared gene expression in cocultures of both osteoblastic (MDA-PCa 2b) and osteolytic (PC-3) prostate cancer cell lines with osteoblasts under bilayer and contact culture conditions. As controls, the prostate cancer cells were cultured alone in the absence of osteoblasts. Under bilayer coculture conditions, there is no physical contact between the prostate cancer cells and the osteoblasts, but each cell line is exposed to soluble factors secreted by both cell types. In contrast, under contact coculture conditions, cancer cells and osteoblasts are both physically in contact and are exposed to soluble factors secreted by both cell types. The control prostate cancer cells cultured alone have no interaction with osteoblasts. The microarray results of the prostate cancer cells cultured alone were compared with those of prostate cancer cells from the bilayer

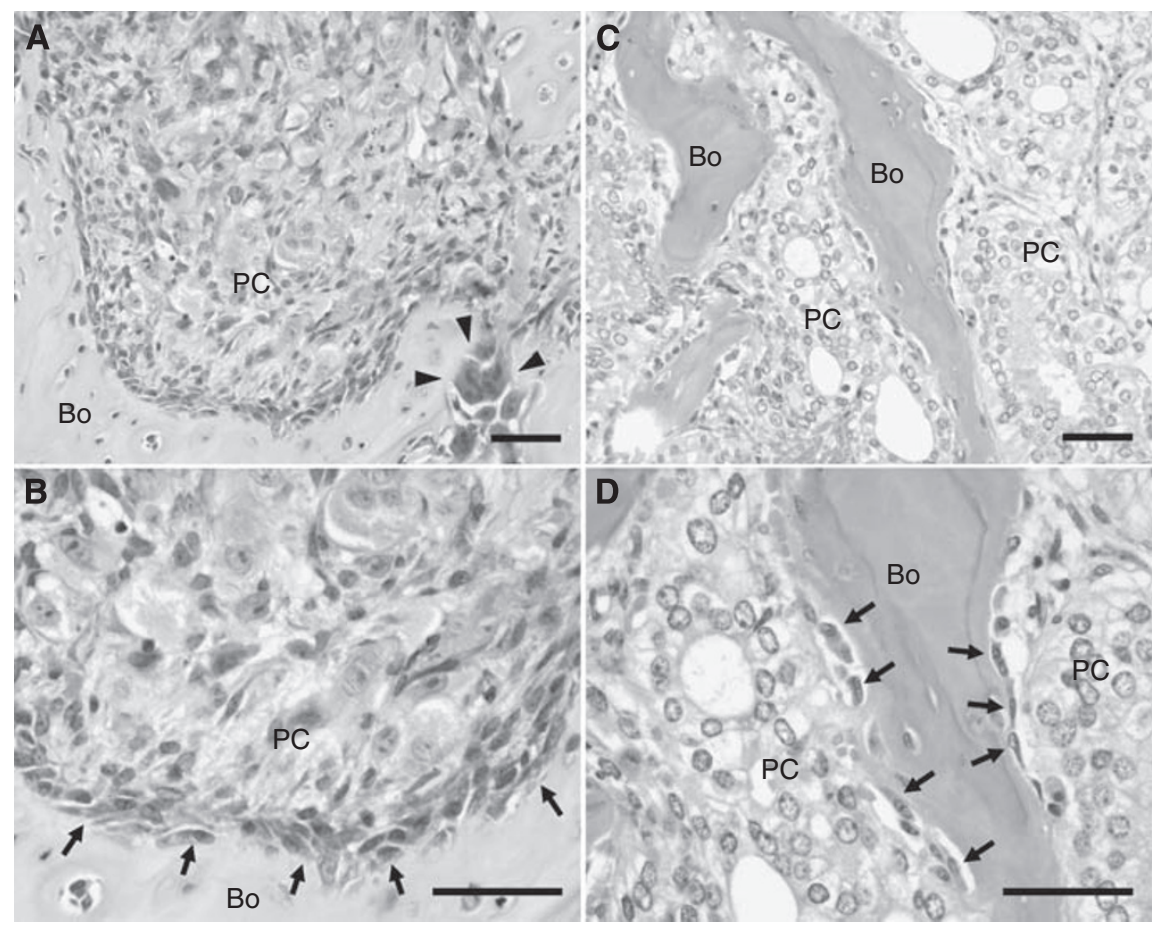

Figure I Histological findings suggesting direct prostate cancer-cell-osteoblast contact in bone metastases. The indicated tissues were fixed and analysed following H\&E staining. (A and B) An osteolytic lesion produced by the growth of PC-3 human prostate cancer cells in the tibia of a nude mouse. The close proximity of PC-3 cells to osteoblasts suggesting direct cancer-cell-osteoblast contact, as well as osteolysis by osteoclasts was observed. (C and D) Representative osteoblastic bone metastases of autopsy cases of prostate cancer. The close proximity of prostate cancer cells to osteoblasts suggesting direct cancer-cell-osteoblast contact was also observed. Arrows, osteoblasts; arrow heads, osteoclasts; Bo, bone; PC, prostate cancer cells. Scale $=50 \mu$ m. 


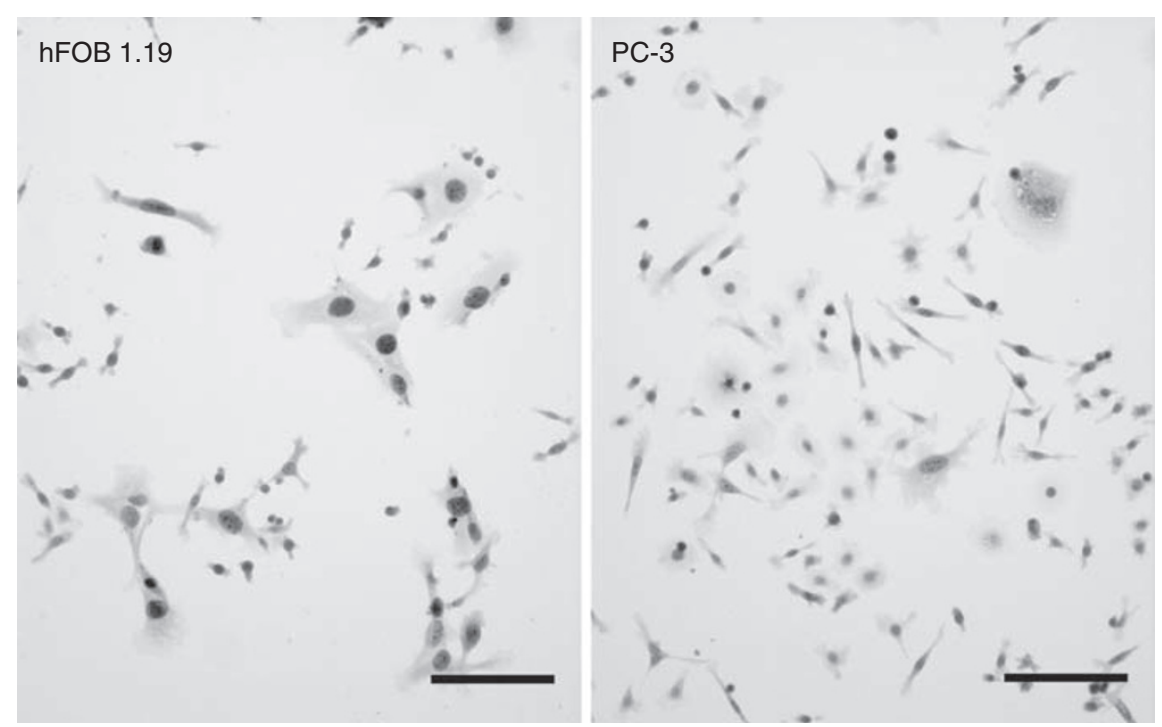

Figure 2 Immunohistochemical analysis of the SV40 large T antigen after sorting of cells in contact cocultures. PC-3 human prostate cancer cells (labelled with $\mathrm{DiOC}_{18}(3)$ ) were mixed and cocultured with $\mathrm{DilC}_{18}$ (3)-labeled human osteoblasts expressing SV40 (hFOBI.19) for $48 \mathrm{~h}$. Cocultured prostate cancer cells $\left(\mathrm{DiOC}_{18}(3)^{+} / \mathrm{DilC}_{18}(3)^{-}\right)$and $\mathrm{hFOBI} .19$ cells $\left(\mathrm{DiOC}_{18}(3)^{-} / \mathrm{DilC}_{18}(3)^{+}\right)$were then separated using flow cytometry. One thousand cells from each sorted cell population were cultured overnight on glass slides and were then immunohistochemically stained for the SV40 large T antigen. Positive staining of the SV40 large $T$ antigen was observed in the nuclei of $\mathrm{hFOBI.19}$ cells $\left(\mathrm{DiOC}_{18}(3)^{-} / \mathrm{DilC}_{18}(3)^{+}\right)$but not in $\mathrm{PC}-3 \mathrm{cells}\left(\mathrm{DiOC}_{18}(3)^{+} / \mathrm{DilC}_{18}(3)^{-}\right)$. Scale $=100 \mu \mathrm{m}$

Table 2 Up-/downregulated genes in PC-3 cells cultured under contact coculture conditions, identified by cDNA microarray analysis

\begin{tabular}{llc}
\hline $\begin{array}{l}\text { Gene bank } \\
\text { accession no. }\end{array}$ & Gene name & $\begin{array}{c}\text { Fold } \\
\text { change }\end{array}$ \\
\hline $\begin{array}{l}\text { Upregulated genes in contact coculture conditions } \\
\text { NM_007 I I5 }\end{array}$ & Tumor necrosis factor, alpha-induced protein 6 & \\
NM_000576 & Interleukin I- $\beta$ & 5.3 \\
NM_000963 & Prostaglandin-endoperoxide synthase 2 (COX2) & 4.4 \\
NM_001442 & Fatty acid binding protein 4, adipocyte & 4.2 \\
NM_000600 & Interleukin 6 (interferon, $\beta$-2) & 4.0 \\
NM_007028 & Tripartite motif-containing 31 & 3.7 \\
NR_003006 & Small Cajal body-specific RNA 6 on chromosome 2 & 3.5 \\
NM_000064 & Complement component 3 & 3.4 \\
& \\
Downregulated genes in contact coculture conditions & \\
NM_003II8 & Secreted protein, acidic, cysteine-rich (osteonectin) & 0.3 \\
\hline
\end{tabular}

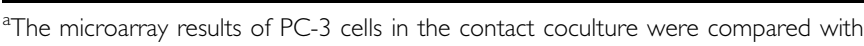
those of cells from the bilayer coculture. The fold change in gene expression that was $>3.0$ or $<0.33$ was considered significant.

coculture. The results of the prostate cancer cells in the bilayer coculture were further compared with those of cells from the contact coculture. A fold change in gene expression that was $>3.0$ or $<0.33$ was considered significant. There was no significant difference in gene expression between PC-3 cells cultured alone and those cocultured under bilayer conditions. This result suggested that soluble factors presents in the coculture did not affect the gene expression in PC-3 cells. In contrast, when the gene expression of PC-3 cells cultured under contact coculture conditions was compared with that of PC-3 cells cultured under bilayer coculture conditions, eight upregulated genes (3.2-5.3fold) and one downregulated gene ( 0.3 -fold) were identified in the contact cocultures (Table 2). Thus, the expression of these genes appeared to be specifically regulated by direct contact between PC-3 cells and osteoblasts. We then determined if these regulated genes might be related to genes that are known to be involved in cancer metastasis and bone remodelling. Four of the eight upregulated genes (IL-1 $\beta$, COX-2, IL-6 and C3) have already been reported to participate in osteoclastogenesis (Mangham et al, 1993; Sato et al, 1993; García-Moreno et al, 2002; Roodman, 2004; Liu et al, 2005; Singh et al, 2007; Bussard et al, 2008). There was no significant difference in the gene expression of MDA-PCa $2 \mathrm{~b}$ cells under any culture conditions.

\section{Validation of cDNA microarray results}

To confirm the microarray results, the mRNA expression of the four osteoclastogenesis-related genes that were upregulated in PC-3 cells following coculture with hFOB1. A total of 19 cells under contact conditions were examined using RT - PCR. Consistent with the cDNA microarray results, upregulation of IL- $1 \beta$, COX-2, IL-6 and C3 mRNA were detected in PC-3 cells under contact coculture conditions compared with under bilayer coculture conditions (Figure 3A).

We next determined the expression of IL- $1 \beta$, COX-2, IL- 6 and C3 in PC-3 cells at the protein level. The protein levels of IL-1 $\beta$, IL- 6 and C3 were measured using ELISA. A PC-3 cell lysate was used for ELISA, rather than culture supernatant, to eliminate the influence of exogenous IL- $1 \beta$, IL- 6 and C3 secreted by osteoblasts in the coculture. The level of IL- 6 in PC-3 cells was significantly higher $(P<0.001)$ under contact coculture conditions than in PC-3 cells under bilayer coculture conditions, whereas the level of IL- $1 \beta$ was not significantly different between the two coculture conditions (Figure 3B). The level of C3 in PC-3 cells was below the limits of detection under both bilayer and contact coculture conditions. Expression of COX-2 was determined by western blotting. The expression level of COX-2 was higher in PC-3 cells under contact coculture conditions than under bilayer coculture conditions (Figure 3C). Expression of COX-2 in the osteolytic bone metastasis model was also examined using immunohistochemistry. PC-3 cells formed solid tumour within the bone microenvironment in this tumour model, and strongly expressed COX-2 at the periphery of the tumour adjacent to the bone (Figure 3D, left). The close proximity of PC-3 cells to osteoblasts suggesting direct cancer-cell-osteoblast 

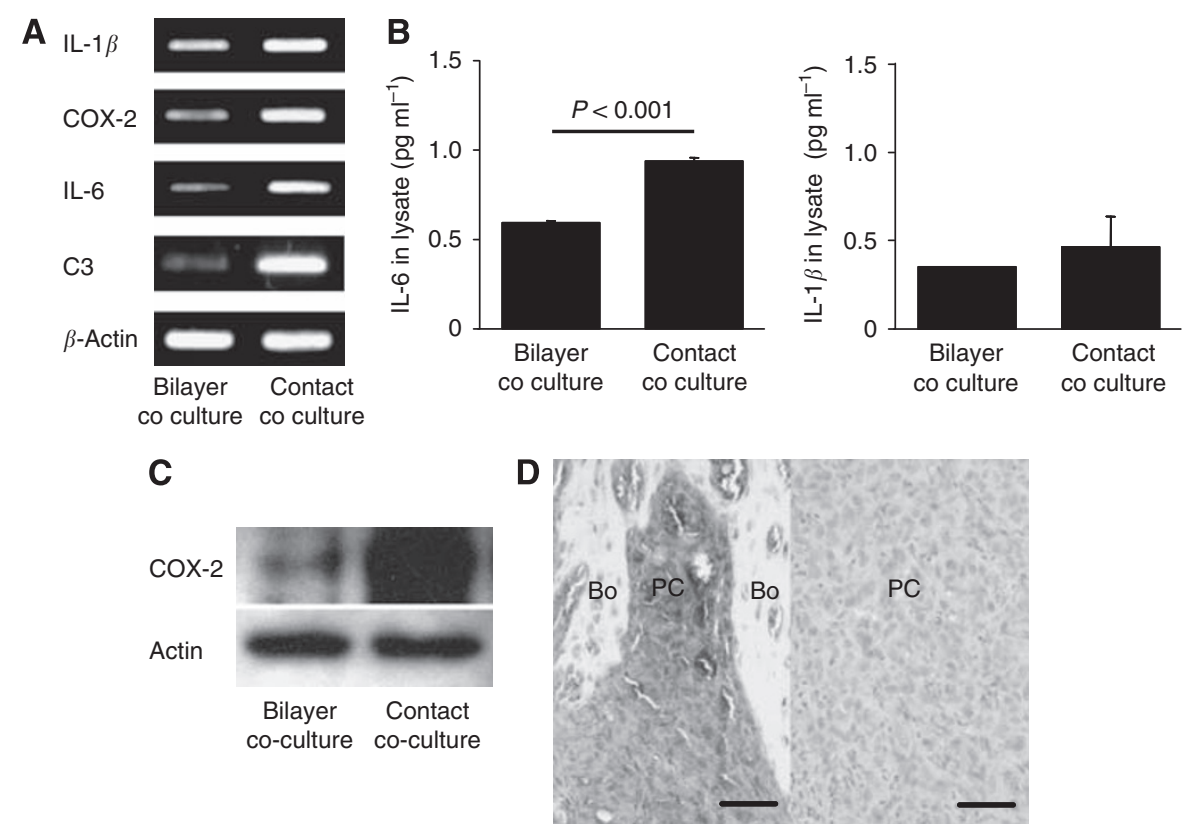

Figure 3 Analysis of IL-I $\beta$, COX-2, IL-6 and C3 expression in PC3 cells cocultured with hFOBI.I9 cells. (A) The mRNA expression of the four osteoclastogenesis-related genes, IL-I $\beta$, COX-2, IL-6 and C3, in PC-3 cells following coculture under contact and bilayer conditions, was analysed using RT-PCR. Consistent with the CDNA microarray results, these genes were upregulated in contact cocultured PC-3 cells compared with bilayer cocultured cells. The primers used for RT-PCR are shown in Table I. (B) Measurement of IL-6 and IL-I $\beta$ levels in PC-3 cells using ELISA. The level of IL-6 was significantly higher $(P<0.00 I)$ in $\mathrm{PC}-3$ cells under contact coculture conditions than under bilayer coculture conditions, whereas IL-I $\beta$ levels did not significantly differ between the two coculture conditions. ELISA was performed using a PC-3 cell lysate. (C) Analysis of COX-2 expression in PC-3 cells by western blotting. Expression of COX-2 was higher in PC-3 cells under contact coculture conditions than under bilayer coculture conditions (D) Immunohistochemical analysis of COX-2 expression in an osteolytic bone metastasis model. Left: Strong expression of COX-2 in PC-3 cells adjacent to the bone. The close proximity of PC-3 cells to osteoblasts suggesting direct cancer-cell-osteoblast contact was observed in this area. Right: very low expression of COX-2 in PC-3 cells distant from the bone. Bo, bone; PC, prostate cancer cells. Scale $=50 \mu \mathrm{m}$.

contact was locally observed in this area. In contrast, in tumour areas that were distant from the bone, COX-2 expression was very low (Figure 3D, right). These results suggest that COX-2 expression in osteolytic prostate cancer cells correlates with physical contact between the cancer cells and osteoblasts in the bone microenvironment.

\section{In vitro osteoclastogenesis}

To examine the effect of physical contact between osteolytic cancer cells and osteoblasts on osteoclastogenic activity of cancer cells, an in vitro osteoclastogenesis assay was performed. In this assay, PC-3 cells that had been grown under contact or bilayer coculture conditions were lysed, and this lysate was then incubated with adherent bone marrow cells in the presence of RANKL and M-CSF for 10 days. The cells were then fixed and differentiated osteoclasts were detected by microscopic observation of TRAP staining. As shown in Figure 4, treatment with a cell lysate from PC-3 cells cocultured with hFOB1.19 cells under bilayer and contact conditions resulted in $20 \pm 3$ and $31 \pm 7$ TRAP-positive cells per field, respectively. The difference in number between the two culture conditions was statistically significant $(P<0.005)$. These results suggest that the osteoclastogenic activity of osteolytic prostate cancer cells is enhanced by physical contact with osteoblasts.

\section{$\mathrm{N}$-cadherin and cadherin-11 neutralisation assay}

We hypothesized that upregulation of osteoclastogenesis-related genes in PC-3 cells in contact cocultures may be induced by adhesion molecules that mediate interactions between PC-3 and hFOB1.19 cells. Both N-cadherin and cadherin-11 are overexpressed in osteoblasts (Marie, 2002; Mbalaviele et al, 2006) and prostate cancer cells (Tomita et al, 2000; Chu et al, 2008) and are considered to have an important role in bone metastasis of prostate cancer. We therefore determined if these cadherins might have a role in the upregulation of osteoclastogenesis-related genes in PC-3 cells under contact coculture conditions. For this purpose, we assayed if neutralisation of these cadherins using specific $\mathrm{N}$-cadherin and cadherin-11 neutralising antibodies might inhibit the observed upregulation of these genes in PC-3 cells. We first confirmed that $\mathrm{N}$-cadherin and cadherin-11 are expressed in both hFOB1.19 and PC-3 cells using RT-PCR (Figure 5A). Following pretreatment of hFOB1.19 cells with the cadherin-11 neutralising antibody, the upregulation of COX-2 and C3 mRNA that occurs in PC-3 cells under contact coculture conditions was inhibited. The ratio in level of COX-2 and $\mathrm{C} 3$ in anti-cadherin-11 antibodytreated cells to that in control antibody-treated cells were 0.49 and 0.60 , respectively. In contrast, the upregulation of IL- $1 \beta$ and IL-6 mRNAs was not. Inversely, pretreatment with the N-cadherinneutralising antibody further increased the upregulation of COX-2 mRNA. The ratio in level of COX-2 in anti-N-cadherin antibodytreated cells to that in control antibody-treated cells was 1.70 (Figure 5B). These results suggest that upregulation of osteoclastogenesis-related genes in PC-3 cells under contact coculture conditions is, at least in part, associated with both $\mathrm{N}$-cadherin and cadherin-11.

\section{DISCUSSION}

In this study, we have shown that physical contact between osteolytic prostate cancer cells and osteoblasts may upregulate the expression of osteoclastogenesis-related genes in prostate cancer 
cells, and enhance osteoclastogenesis. Microarray analysis of genes that were only expressed under contact coculture conditions and not under bilayer conditions, were considered to be specifically induced by physical contact between prostate cancer cells and osteoblasts.

We identified eight upregulated genes and one downregulated gene in PC-3 cells that were regulated only under contact coculture

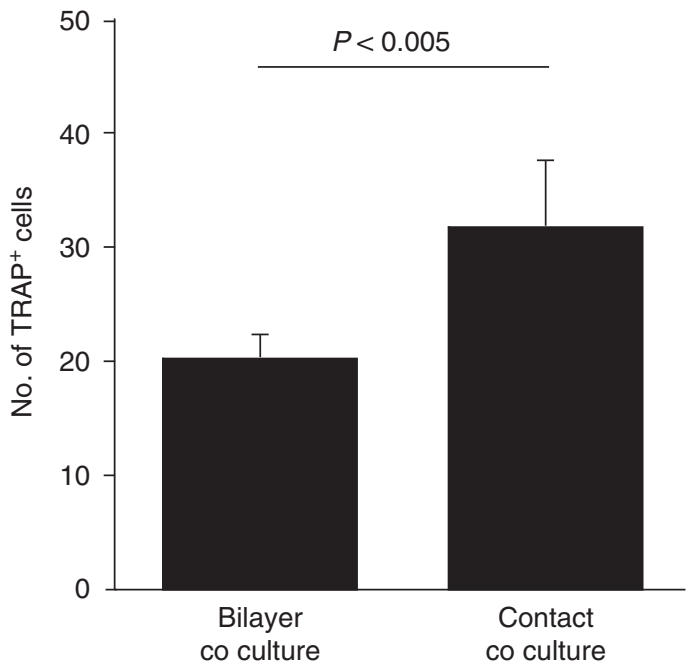

Figure 4 Osteoclastogenic activity of $\mathrm{PC}-3$ cells cocultured with hFOBI.19 cells. The effect of addition of a cell lysate from PC-3 cells, grown under contact or bilayer coculture conditions, on osteoclastogenesis of bone marrow cells in an in vitro osteoclastogenesis assay, was determined by microscopic analysis of the number of tartrate-resistant acid phosphatase (TRAP) cells. The number of TRAP-positive cells in more than five microscopic fields was counted ( $\times 200$ magnification). Osteoclastogenesis was significantly enhanced by the cell lysate of PC-3 cells grown under contact coculture conditions compared with osteoclastogenesis with a lysate of cells grown under bilayer coculture conditions $(P<0.005)$. Data are representative of two separate experiments. conditions. Interaction between cancer cells and osteoblasts has been previously studied using in vitro coculture systems in which conditioned medium or cell culture inserts have been employed. The results of these types of studies only reflect the effects of soluble factors and not of direct cell - cell contact. In our study, we did not detect any genes that were differentially expressed because of coculture of PC-3 cells and osteoblasts under bilayer conditions, where the PC-3 cells are only exposed to soluble factors produced by the osteoblasts. These results suggest that the contact coculture system may be useful for understanding the molecular mechanisms of interaction between prostate cancer cells and osteoblasts and for the detection of new molecular targets for the treatment of bone metastasis. Wang et al previously analysed gene expression in a contact coculture of PC-3 cells and rat bone marrow stromal cells. They detected 18 genes in PC-3 cells and 10 genes in bone marrow stromal cells, expression of which was regulated only in the physical contact coculture system (Wang et al, 2006). However, the regulated genes that they detected did not overlap with the genes that were regulated in our coculture system, indicating that osteoblasts and bone marrow stromal cells have different roles in prostate cancer bone metastasis.

Four of the eight genes that we found to be upregulated in PC-3 cells under contact coculture conditions, that is, IL- $1 \beta$, COX-2, IL-6 and C3 have already been reported to participate in osteoclastogenesis (Mangham et al, 1993; Sato et al, 1993; García-Moreno et al, 2002; Roodman, 2004; Liu et al, 2005; Singh et al, 2007; Bussard et al, 2008).

Cyclooxygenase- 2 is an inducible prostaglandin synthesis enzyme, and is indirectly involved in bone resorption and osteoclastogenesis through prostaglandin $\mathrm{E}_{2} \quad\left(\mathrm{PGE}_{2}\right)$ (Akatsu et al, 1989; Ohshiba et al, 2003). The expression of COX-2 is upregulated in many cancers. The product of COX-2, prostaglandin $\mathrm{H}_{2}$, is converted by $\mathrm{PGE}_{2}$ synthase into $\mathrm{PGE}_{2}$, which can stimulate cancer progression (Menter et al, 2010). Cyclooxygenase-2 is overexpressed in primary prostate cancer with metastatic potential and its expression is associated with death from prostate carcinoma (Richardsen et al, 2010). Previously we have shown that neutralisation of $\mathrm{PGE}_{2}$ using a soluble E-prostanoid receptor 2, inhibits the growth of PC-3 cells and tumour-induced osteoclastogenesis in a mouse model of bone metastasis (Takahashi et al, 2008).
A

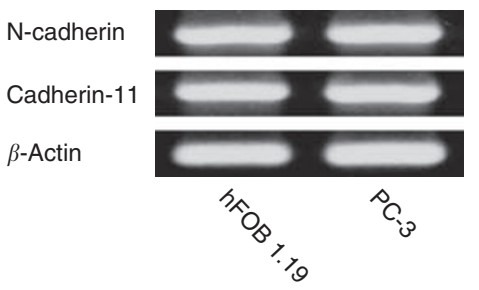

B

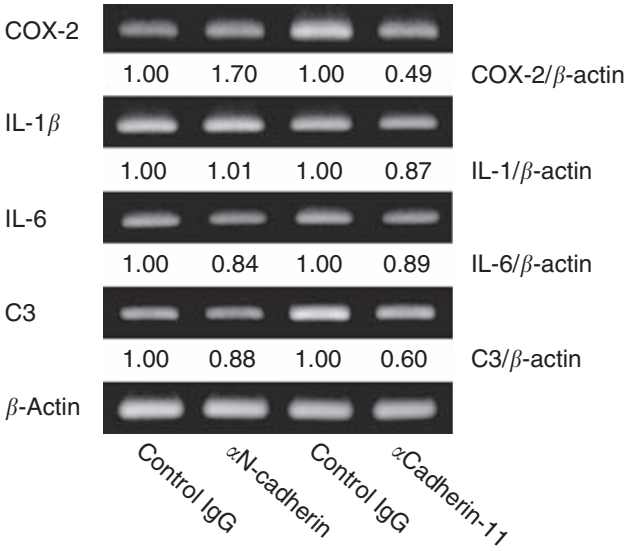

Figure 5 Effect of the blockade of N-cadherin- and cadherin-II-dependent cell adhesion between PC-3 and hFOBI.I9 cells. (A) Confirmation of $\mathrm{N}$-cadherin and cadherin- I I expression in both PC-3 cells and hFOBI. 19 cells using RT-PCR. (B) Effects of N-cadherin or cadherin-I I neutralising antibodies on osteoclastogenesis-related gene expression in $\mathrm{PC}-3$ cells under contact coculture conditions. The hFOBI. 19 cells were pretreated with $\mathrm{N}$-cadherin- or cadherin-I I-neutralising antibodies for $30 \mathrm{~min}$ at $37^{\circ} \mathrm{C}$, and then contact coculture with PC-3 cells was initiated. After $48 \mathrm{~h}$, RNA was extracted from sorted PC-3 cells and was used as a template for RT-PCR to analyze the expression of the indicated osteoclastogenic genes. Signal intensities of each band were quantified by using NIHimage 1.62 software and normalised by that of $\beta$-actin. Data are representative of two separate experiments. The cadherin-I I neutralising antibody inhibited the upregulation of COX-2 and C3 mRNA, whereas the N-cadherin neutralising antibody further induced the upregulation of COX-2 mRNA. 
Thus, our microarray results, that COX-2 expression is only upregulated in osteolytic PC-3 cells and not in osteoblastic MDA-PCa $2 \mathrm{~b}$ cells, is consistent with the evidence that COX-2 and $\mathrm{PGE}_{2}$ are key molecules for osteolytic bone metastasis. Furthermore, immunohistochemical analysis of an osteolytic bone metastasis model showed that COX-2 is strongly expressed in PC-3 cells that are adjacent to the bone and are locally in contact with osteoblasts, and is weakly expressed in PC-3 cells that are distant from the bone. These results suggest that the contact and bilayer coculture system may mimic the in vivo situation of metastatic cancer cells adjacent to and distant from the bone, respectively.

Interleukin-6 is a mediator of $\mathrm{PGE}_{2}$-induced suppression of osteoprotegerin production by osteoblasts and enhances osteoclast differentiation (Liu et al, 2005). Interleukin-6 and the IL-6 receptor have been identified in human prostate carcinoma (Siegsmund et al, 1994) and IL-6 acts as an autocrine and paracrine growth factor in androgen-refractory prostate cancer cells including PC-3 cells (Chung et al, 1999). Immunohistochemical investigation of prostate cancer metastases and xenografts showed that IL-6 is expressed in the majority of prostate cancer bone metastases and to a lesser extent in prostate cancer soft tissue metastases (Morrissey et al, 2010). Our data is consistent with the results of these reports.

IL- $1 \beta$ has been found to increase the formation as well as the resorptive capacity of osteoclasts in culture (Trebec-Reynolds et al, 2010 ), and can induce IL-8 production in prostate cancer cells, which promotes prostate cancer cell proliferation and migration (Tsai et al, 2009). Although we confirmed the cDNA microarray result of IL- $1 \beta$ mRNA upregulation using RT-PCR, the protein level of IL- $1 \beta$ in PC-3 cell lysates was not significantly different under bilayer and contact coculture conditions. The reason for this discrepancy is unknown, but it may involve posttranscriptional or posttranslational regulatory mechanisms.

C3 participates in osteoclast development by potentiating M-CSF-dependent proliferation of bone marrow cells and induction of osteoclast differentiation (Sato et al, 1993). The concentrations of C3 in prostatic fluid are significantly greater in patients with prostate cancer than those with benign prostate hyperplasia. However, in our study it was not possible to determine differences in the level of $\mathrm{C} 3$ protein between PC-3 cells under bilayer and contact coculture conditions, as the $\mathrm{C} 3$ protein level was below the limits of detection of ELISA analysis.

The roles of other four upregulated genes, that is, tumour necrosis factor, alpha-induced protein 6 , fatty acid binding protein 4 , tripartite motif-containing 31, small Cajal body-specific RNA 6 on chromosome 2 and one downregulated gene, that is, secreted protein acidic and rich in cysteine (SPARC; also known as osteonectin) on osteoclastogenesis and bone metastasis must be clarified in future studies. Especially, SPARC has been assumed to be important in human prostate cancer bone metastasis as a major bone-derived chemoattractant for prostate cancer cells (Jacob et al, 1999). On the other hand, downregulation of endogenous SPARC by small interference RNA accelerates prostate cancer cell-line proliferation and matrix invasiveness (Said et al, 2009). Participation of SPARC in osteoclastogenesis is unclear. However, SPARC stimulates the synthesis of osteoprotegerin, a physiological inhibitor of osteoclastogenesis, in human periodontal ligament cells (Fujita et al, 2002).

We showed that PC-3 cells that were cocultured with hFOB1.19 cells under contact conditions had significantly higher osteoclastogenic activity in an in vitro osteoclastogenesis assay than cells cultured under bilayer conditions. On the basis of the observed protein expression levels, it would appear that COX-2 and IL-6, rather than IL-1 $\beta$ and $\mathrm{C} 3$, are the major molecules that influence this enhancement of osteoclastogenesis in the contact coculture system.

Cell adhesion molecules have been suggested to have a primary role in the interactions between tumour cells and host environment (Michigami et al, 2000; Cowin et al, 2005). In particular, cadherins have been proposed to function as tumour promoter factors during cancer invasion and organ preferential metastasis (Pishvaian et al, 1999; Gravdal et al, 2007). N-cadherin and cadherin-11 are transmembrane calcium-dependent and homophilic cell-cell adhesion molecules. These molecules have been detected in prostate cancers (Tomita et al, 2000) and in osteoblasts (Cheng et al, 1998; Mbalaviele et al, 2006) and have been reported to be implicated in cancer invasion and human osteoblast differentiation (Kii et al, 2004; Chu et al, 2008). These finding led us to hypothesize that $\mathrm{N}$-cadherin and cadherin-11 may participate in the upregulation of osteoclastogenesis-related genes that was mediated by physical contact between PC-3 and hFOB1.19 cells. Consistent with previous studies, we found that $\mathrm{N}$-cadherin and cadherin-11 were both expressed in PC-3 and hFOB1.19 cells. Pre-treatment of hFOB1.19 cells with cadherin-11-neutralising antibody before initiation of the coculture inhibited the upregulation of COX-2 and C3 mRNA that was induced in PC-3 cells under contact coculture conditions. In contrast, pre-treatment with $\mathrm{N}$-cadherin neutralising antibody upregulated COX-2 mRNA in PC-3 cells under contact coculture conditions. These data suggest that cadherin-11 and $\mathrm{N}$-cadherin are involved in the process of osteoclastogenesis that is induced by physical contact between osteolytic prostate cancer cells and osteoblasts.

There is a great deal of evidence indicating that interaction between prostate cancer cells and osteoblasts has an important role in the survival and growth of metastatic cancer cells in a bone microenvironment (Logothetis and Lin, 2005; Morrissey et al, 2010). Physical contact between cancer cells and osteoblasts has been suggested to be involved in these processes. However, when we histologically analysed osteolytic tumours that were produced by intratibial injection of PC-3 cells into nude mice, the bone surfaces facing the tumours were extensively lysed by osteoclasts. Although residual osteoblasts and the close proximity of PC-3 cells to osteoblasts suggesting direct cancer-cell-osteoblast contact was observed in some areas (Figure 1A), the question remained whether this type of cell-cell contact is common in human cases of bone metastases or not. However, in all 37 autopsy cases with osteoblastic or osteolytic bone metastases that we reviewed, the close proximity of cancer cells to osteoblasts suggesting direct cancer-cell-osteoblast contact was observed to varying extents. Although we could not confirm direct cancer-cell-osteoblast contact by electron microscopy, these results suggest that direct cancer-cell-osteoblast contact is common, at least in advanced bone metastases. In future studies, it must be clarified whether metastatic cancer cells physically contact with osteoblasts in early bone metastasis, either as a single cell or as a small focus of cells.

In this study, we have shown that direct metastatic cancer-cellosteoblast contact likely to be a common event in cases with advanced bone metastases. We further show that physical contact between osteolytic prostate cancer cells and osteoblasts may enhance the osteoclastogenic activity of prostate cancer cells by inducing upregulation of the gene expression of specific osteoclastogenesis-related genes. Additionally, this process is, at least in part, cadherin-11 dependent. These data provide evidence to support the design of new therapies of prostate cancer bone metastasis that target direct cancer-cell-osteoblast contact.

\section{ACKNOWLEDGEMENTS}

We thank Megumi Kume and Hitomi Umemoto for technical assistance. This work was supported by a Grant-in-Aid for Scientific Research (No. 21390442 to H.K.) provided by the Ministry of Education, Culture, Sports, Science and Technology, Japan, and was partly supported by an Extramural Collaborative Research Grant from the Cancer Research Institute, Kanazawa University. 


\section{REFERENCES}

Akatsu T, Takahashi N, Debari K, Morita I, Murota S, Nagata N, Takatani O, Suda T (1989) Prostaglandins promote osteoclastlike cell formation by a mechanism involving cyclic adenosine $3^{\prime}, 5^{\prime}$-monophosphate in mouse bone marrow cell cultures. J Bone Miner Res 4(1): 29-35

Bubendorf L, Schopfer A, Wagner U, Sauter G, Moch H, Willi N, Gasser TC, Mihatsch MJ (2000) Metastatic patterns of prostate cancer: an autopsy study of 1589 patients. Human Pathol 31(5): 578-583

Bussard KM, Gay CV, Mastro AM (2008) The bone microenvironment in metastasis; what is special about bone? Review. Cancer Metastasis Rev 27(1): $41-55$

Charhon SA, Chapuy MC, Delvin EE, Valentin-Opran A, Edouard CM, Meunier PJ (1983) Histomorphometric analysis of sclerotic bone metastases from prostatic carcinoma special reference to osteomalacia. Cancer 51(5): 918-924

Cheng SL, Lecanda F, Davidson MK, Warlow PM, Zhang SF, Zhang L, Suzuki S, St John T, Civitelli R (1998) Human osteoblasts express a repertoire of cadherins, which are critical for BMP-2-induced osteogenic differentiation. I Bone Miner Res 13(4): 633-644

Cheville JC, Tindall D, Boelter C, Jenkins R, Lohse CM, Pankratz VS, Sebo TJ, Davis B, Blute ML (2002) Metastatic prostate carcinoma to bone: clinical and pathologic features associated with cancer-specific survival. Cancer 95(5): $1028-1036$

Chu K, Cheng CJ, Ye X, Lee YC, Zurita AJ, Chen DT, Yu-Lee LY, Zhang S, Yeh ET, Hu MC, Logothetis CJ, Lin SH (2008) Cadherin-11 promotes the metastasis of prostate cancer cells to bone. Mol Cancer Res 6(8): 1259-1267

Chung TD, Yu JJ, Spiotto MT, Bartkowski M, Simons JW (1999) Characterization of the role of IL- 6 in the progression of prostate cancer. Prostate 38(3): 199-207

Cowin P, Rowlands TM, Hatsell SJ (2005) Cadherins and catenins in breast cancer. Curr Opin Cell Biol 17(5): 499-508

Fizazi K, Yang J, Peleg S, Sikes CR, Kreimann EL, Daliani D, Olive M, Raymond KA, Janus TJ, Logothetis CJ, Karsenty G, Navone NM (2003) Prostate cancer cells-osteoblast interaction shifts expression of growth/ survival-related genes in prostate cancer and reduces expression of osteoprotegerin in osteoblasts. Clin Cancer Res 9(7): 2587-2597

Fujita T, Shiba H, Sakata M, Uchida Y, Nakamura S, Kurihara H (2002) SPARC stimulates the synthesis of OPG/OCIF, MMP-2 and DNA in human periodontal ligament cells. J Oral Pathol Med 31(6): 345-352

García-Moreno C, Méndez-Dávila C, de La Piedra C, Castro-Errecaborde NA, Traba ML (2002) Human prostatic carcinoma cells produce an increase in the synthesis of interleukin-6 by human osteoblasts. Prostate 50(4): $241-246$

Gravdal K, Halvorsen OJ, Haukaas SA, Akslen LA (2007) A switch from $\mathrm{E}$-cadherin to $\mathrm{N}$-cadherin expression indicates epithelial to mesenchymal transition and is of strong and independent importance for the progress of prostate cancer. Clin Cancer Res 13(23): 7003-7011

Harris SA, Enger RJ, Riggs BL, Spelsberg TC (1995) Development and characterization of a conditionally immortalized human fetal osteoblastic cell line. J Bone Miner Res 10(2): 178-186

Hullinger TG, Taichman RS, Linseman DA, Somerman MJ (2000) Secretory products from PC-3 and MCF-7 tumor cell lines upregulate osteopontin in MC3T3-E1 cells. J Cell Biochem 78(4): 607-616

Jacob K, Webber M, Benayahu D, Kleinman HK (1999) Osteonectin promotes prostate cancer cell migration and invasion: a possible mechanism for metastasis to bone. Cancer Res 59(17): 4453-4457

Jemal A, Siegel R, Ward E, Hao Y, Xu J, Murray T, Thun MJ (2008) Cancer statistics, 2008. CA Cancer I Clin 58(2): $71-96$

Kido J, Yamauchi N, Ohishi K, Kataoka M, Nishikawa S, Nakamura T, Kadono H, Ikedo D, Ueno A, Nonomura N, Okuyama A, Nagata T (1997) Inhibition of osteoblastic cell differentiation by conditioned medium derived from the human prostatic cancer cell line PC-3 in vitro. J Cell Biochem 67(2): 248-256

Kii I, Amizuka N, Shimomura J, Saga Y, Kudo A (2004) Cell-cell interaction mediated by cadherin-11 directly regulates the differentiation of mesenchymal cells into the cells of the osteo-lineage and the chondrolineage. J Bone Miner Res 19(11): 1840-1849

Lang SH, Miller WR, Habib FK (1995) Stimulation of human prostate cancer cell lines by factors present in human osteoblast-like cells but not in bone marrow. Prostate 27(5): 287-293

Liu XH, Kirschenbaum A, Yao S, Levine AC (2005) Cross-talk between the interleukin-6 and prostaglandin $\mathrm{E}(2)$ signaling systems results in enhancement of osteoclastogenesi. Endocrinology 146(4): $1991-1998$
Logothetis CJ, Lin SH (2005) Osteoblasts in prostate cancer metastasis to bone. Nat Rev Cancer 5(1): 21-28

Mangham DC, Scoones DJ, Drayson MT (1993) Complement and the recruitment of mononuclear osteoclasts. J Clin Pathol 46(6): 517-521

Marie PJ (2002) Role of N-cadherin in bone formation. J Cell Physiol 190(3): $297-305$

Martínez J, Silva S, Santibanez JF (1996) Prostate-derived soluble factors block osteoblast differentiation in culture. J Cell Biochem 61(1): 18-25

Mbalaviele G, Shin CS, Civitelli R (2006) Cell-cell adhesion and signaling through cadherins: connecting bone cells in their microenvironment. J Bone Miner Res 21(12): 1821-1827

Menter DG, Schilsky RL, DuBois RN (2010) Cyclooxygenase-2 and cancer treatment: understanding the risk should be worth the reward. Clin Cancer Res 16(5): 1384-1390

Michigami T, Shimizu N, Williams PJ, Niewolna M, Dallas SL, Mundy GR, Yoneda T (2000) Cell-cell contact between marrow stromal cells and myeloma cells via VCAM-1 and alpha(4)beta(1)-integrin enhances production of osteoclast-stimulating activity. Blood 96(5): 1953 - 1960

Morrissey C, Lai JS, Brown LG, Wang YC, Roudier MP, Coleman IM, Gulati R, Vakar-Lopez F, True LD, Corey E, Nelson PS, Vessella RL (2010) The expression of osteoclastogenesis-associated factors and osteoblast response to osteolytic prostate cancer cells. Prostate 70(4): $412-424$

Mundy GR (2002) Metastasis to bone: causes, consequences and therapeutic opportunities. Nat Rev Cancer 2(8): 584-593

Ohshiba T, Miyaura C, Ito A (2003) Role of prostaglandin E produced by osteoblasts in osteolysis due to bone metastasis. Biochem Biophys Res Commun 300(4): $957-964$

Pishvaian MJ, Feltes CM, Thompson P, Bussemakers MJ, Schalken JA, Byers SW (1999) Cadherin-11 is expressed in invasive breast cancer cell lines. Cancer Res 59(4): 947 - 952

Richardsen E, Uglehus RD, Due J, Busch C, Busund LT (2010) COX-2 is overexpressed in primary prostate cancer with metastatic potential and may predict survival. A comparison study between COX-2, TGF-beta, IL-10 and Ki67. Cancer Epidemiol 34(3): 316-322

Roodman GD (2004) Mechanisms of bone metastasis. Review. N Engl J Med 350(16): $1655-1664$

Roudier MP, True LD, Higano CS, Vesselle H, Ellis W, Lange P, Vessella RL (2003) Phenotypic heterogeneity of end-stage prostate carcinoma metastatic to bone. Hum Pathol 34(7): 646-653

Said N, Frierson Jr HF, Chernauskas D, Conaway M, Motamed K, Theodorescu D (2009) The role of SPARC in the TRAMP model of prostate carcinogenesis and progression. Oncogene 28(39): 3487-3498

Sato T, Abe E, Jin CH, Hong MH, Katagiri T, Kinoshita T, Amizuka N, Ozawa H, Suda T (1993) The biological roles of the third component of complement in osteoclast formation. Endocrinology 133(1): $397-404$

Siegsmund MJ, Yamazaki H, Pastan I (1994) Interleukin 6 receptor mRNA in prostate carcinomas and benign prostate hyperplasia. J Urol 151(5): 1396 - 1399

Sim HG, Cheng CW (2005) Changing demography of prostate cancer in Asia. Eur J Cancer 41(6): 834-845

Singh B, Berry JA, Shoher A, Ayers GD, Wei C, Lucci A (2007) COX-2 involvement in breast cancer metastasis to bone. Oncogene 26(26): 3789-3796

Takahashi T, Uehara H, Bando Y, Izumi K (2008) Soluble EP2 neutralizes prostaglandin E2-induced cell signaling and inhibits osteolytic tumor growth. Mol Cancer Ther 7(9): 2807-2816

Tomita K, van Bokhoven A, van Leenders GJ, Ruijter ET, Jansen CF, Bussemakers MJ, Schalken JA (2000) Cadherin switching in human prostate cancer progression. Cancer Res 60(13): 3650-3654

Trebec-Reynolds DP, Voronov I, Heersche JN, Manolson MF (2010) IL-1alpha and IL-1beta have different effects on formation and activity of large osteoclasts. J Cell Biochem 109(5): 975-982

Tsai CY, Lee TS, Kou YR, Wu YL (2009) Glucosamine inhibits IL-1betamediated IL-8 production in prostate cancer cells by MAPK attenuation. $J$ Cell Biochem 108(2): 489-498

Uehara H, Kim SJ, Karashima T, Shepherd DL, Fan D, Tsan R, Killion JJ, Logothetis C, Mathew P, Fidler IJ (2003) Effects of blocking platelet-derived growth factor-receptor signaling in a mouse model of experimental prostate cancer bone metastases. J Natl Cancer Inst 95(6): 458-470

Wang J, Levenson AS, Satcher RL (2006) Identification of a unique set of genes altered during cell-cell contact in an in vitro model of prostate cancer bone metastasis. Int I Mol Med 17(5): 849-856

Yin JJ, Pollock CB, Kelly K (2005) Mechanisms of cancer metastasis to the bone. Cell Research 15(1): 57-62 